Article

\title{
Promoting Recycling of Mixed Waste Polymers in Wood-Polymer Composites Using Compatibilizers
}

\author{
Ossi Martikka *(D) and Timo Kärki \\ Fiber Composite Laboratory, School of Energy Systems, Lappeenranta-Lahti University of Technology LUT, \\ 53850 Lappeenranta, Finland; timo.karki@lut.fi \\ * Correspondence: ossi.martikka@lut.fi; Tel.: +358-40-707-8636
}

Received: 30 November 2018; Accepted: 8 January 2019; Published: 12 January 2019

check for updates

\begin{abstract}
Millions of tons of plastics are produced and consumed annually and should be recycled in a sustainable way. The effects of different compatibilizers on the properties of wood-mixed waste polymer composites are studied to promote recycling of plastics and to determine the potential of using waste plastics in composites. The effect of different addition levels and blending of compatibilizers is examined as well. The studied properties are microstructure, tensile and flexural properties, impact strength, and water absorption and thickness swelling in immersion. The results show that the addition of the selected compatibilizers improved the properties of wood-mixed waste polymer composites remarkably—all the studied mechanical properties and moisture resistance were improved by $50 \%$ or more. The effects depend strongly on the level of addition and the compatibilizer used. Findings show that compatibilization provides a feasible means to recycle waste plastics as feedstock for wood-plastic composites.
\end{abstract}

Keywords: wood-polymer composites; compatibilizers; waste polymer; waste plastics; recycling; WPC; mechanical properties; moisture resistance

\section{Introduction}

The global production of plastic materials in 2016 was 335 million tons, and in Europe, plastic demand totaled 60 million tons in the same year. From that amount, different polyolefin (i.e., polyethylene and polypropylene) grades composed 49.1\%. In Europe, in the year 2016, 27.1 million tons of post-consumer waste was collected, of which less than a third, $31.1 \%$, was recycled; $41.6 \%$ was consumed in energy recovery but still $27.3 \%$ went to landfill [1]. It has been estimated that approximately $4 \%$ of global oil and gas production is used as raw material for plastics production, and in addition to that, a similar amount of fossil fuel is consumed to provide the energy needed for the production [2].

Both incineration and disposal of wastes and energy production needed for producing virgin materials create carbon dioxide emissions. Carbon dioxide is the primary greenhouse gas produced by human activities and has a notable influence in promoting climate change [3,4]. All these factors promote recycling materials found in waste streams. Recycling and reusing materials is not only important ecologically but also economically, as the cost of discarding waste has increased and can be expected to continue to increase, so multiple strong drivers promoting the reuse of waste materials exist. During the past few years, in addition to growing environmental awareness, also legislative actions, e.g., Directive 2008/98/EC on waste [5] (Figure 1.), have strongly encouraged the development of new uses and applications for discarded materials including waste plastics. 


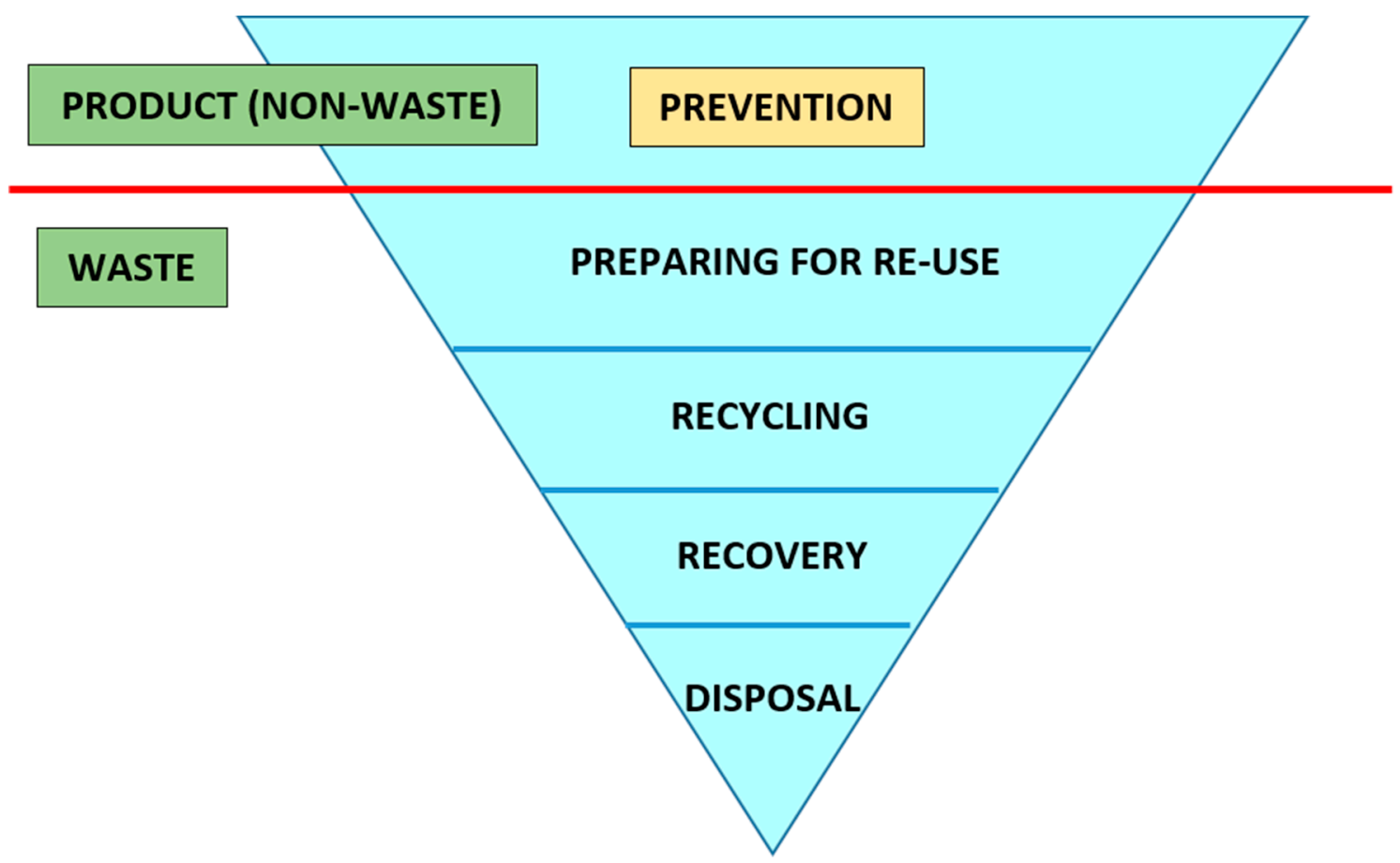

Figure 1. Waste management hierarchy in the EU.

In order to decrease the use of virgin plastics made from non-renewable fossil oil, it would be environmentally sustainable to reclaim plastics from waste streams and to recycle them with minimal effort. The properties of commingled plastics are often poor, so upgrading their performance to meet the requirements of industry and market is crucial. Unfortunately, that is challenging both from economical and technical perspectives [6]. For recycling of plastic waste, mechanical recycling is the most commonly used process, which typically consists of material collection, sorting, washing and grinding [7]. If the process enables substitution of virgin polymers in industrial applications, high ecological benefits can be achieved [8]. The current methods used for the sorting of mixed plastic waste depend on the differences in various properties of plastics. These methods rely on spectral, optic, electrostatic and gravimetric differences of the materials, i.e., their physical and chemical properties [9]. The most common plastic sorts, polyolefins (i.e., polyethylenes and polypropylene), are close to each other not only chemically but also in density, rendering the simplest mechanical separation methods futile. On the other hand, this indicates that, e.g., polyolefins can be extracted from waste streams simultaneously by e.g., water sink-float method, which is technically simple and inexpensive to operate $[9,10]$.

Unfortunately, most polymers are not compatible with each other and also contain impurities, especially if they originate from waste streams. Even in the case of polyolefins, simple mixing of different waste polymers leads typically into an immiscible blend, which has limited or no commercial use due to its inadequate mechanical properties. The immiscible blends lack strong interfacial bonding, resulting also in weak morphological stability, creating an increased risk of phase separation in further processing and use $[6,11]$. In order to overcome these shortcomings, compatibilizing agents can be used. They promote miscibility by lowering interfacial tension between the polymers, hence enhancing the interfacial adhesion. This results in a more stable morphology and more uniform distribution of the dispersed phase [12]. Wood-polymer composites (WPC) are materials or products consisting of one or more natural fibres or flours and one or a mixture of polymer(s). The natural fibres and flours come from different sources, and different polymers, virgin or recycled, are used. Currently, the main applications of WPC products are decking, cladding, panelling, fencing and furniture [13]. To improve the mechanical properties of WPCs, good adhesion between the wood fibre and polymer 
matrix is required. Unfortunately, both components are naturally incompatible due to the hydrophilic nature of wood materials and hydrophobic nature of polymers. Compatibility in the composite can be improved by using either physical or chemical modification of the polymer or wood fibre or by using compatibilizers/coupling agents [14]. Compatibilizers/coupling agents can improve the performance of WPC significantly. Klyosov [15] states that properly employed coupling agents can double the tensile and flexural strengths of WPCs, increase the stiffness up to $40 \%$ depending on the test method, at least double the impact resistance, and increase the density and decrease the water absorption by two to four times, depending on the duration of immersion.

As WPCs are a mixture of materials by nature, it can be speculated that reusing mixed waste plastics could be easier within composites than as pure raw materials [16] and also gain environmental benefits compared to the use of conventional virgin plastics [17]. The use of recycled plastics in WPCs in order to produce more environmentally friendly materials has also drawn the attention of many researchers, suggesting the potential of using recycled plastics. It has been shown that compatibilizers can improve the properties of wood-waste plastic composites $[9,18-26]$, but the focus has not been on evaluating the potential and effects of multiple compatibilizers. In the case of mixed waste plastics, immiscibility of different polymers combined with the natural incompatibility between wood material and the polymer matrix is a challenge in utilizing mixed waste plastics in WPCs. However, the compatibilizers used in WPC are typically maleated/maleic grafted polyolefins [27,28], showing improved properties also in WPCs made from PE-PP blends [29]. Maleic grafted polyolefins can also be used for the compatibilization of polymer blends [30], suggesting that the use of maleated compounds in WPCs made of mixed waste plastics could provide improved performance.

There are strong environmental and legislative drivers towards utilizing plastic waste with other methods than disposal. Composites are naturally mixtures of different materials, so it is reasonable to expect that it would be easier and less expensive to utilize mixed waste plastics in them [16]. As noted above, WPCs may be made from recycled plastics, and in general, the properties of WPCs can be improved by the addition of compatibilizers. In this study, the possibility of improving the properties of WPCs made from commingled plastic waste with the addition of compatibilizers is examined in order to find new, feasible means for recycling and use for the millions of tons of plastic waste produced annually. The effect of different levels of addition of compatibilizers and the potential of compatibilizer blends on the properties of WPCs is also evaluated.

\section{Results}

\subsection{Physical Properties}

\section{Microstructure}

The SEM images taken have been combined into Figure 2. The materials shown are (a): NC, (b): N525-3, (c): N525-7, (d): N416-3, (e): N416-7, (f): CM-3, (g): CM-7, (h): MAM-3 and (i): MAM-7. In general, the wood fibres visible were not broken; pull-outs or intact wooden parts could be seen. However, with materials N525-7 and MAM-7, also shattered wood particles/fibres were found (Figure 3). 


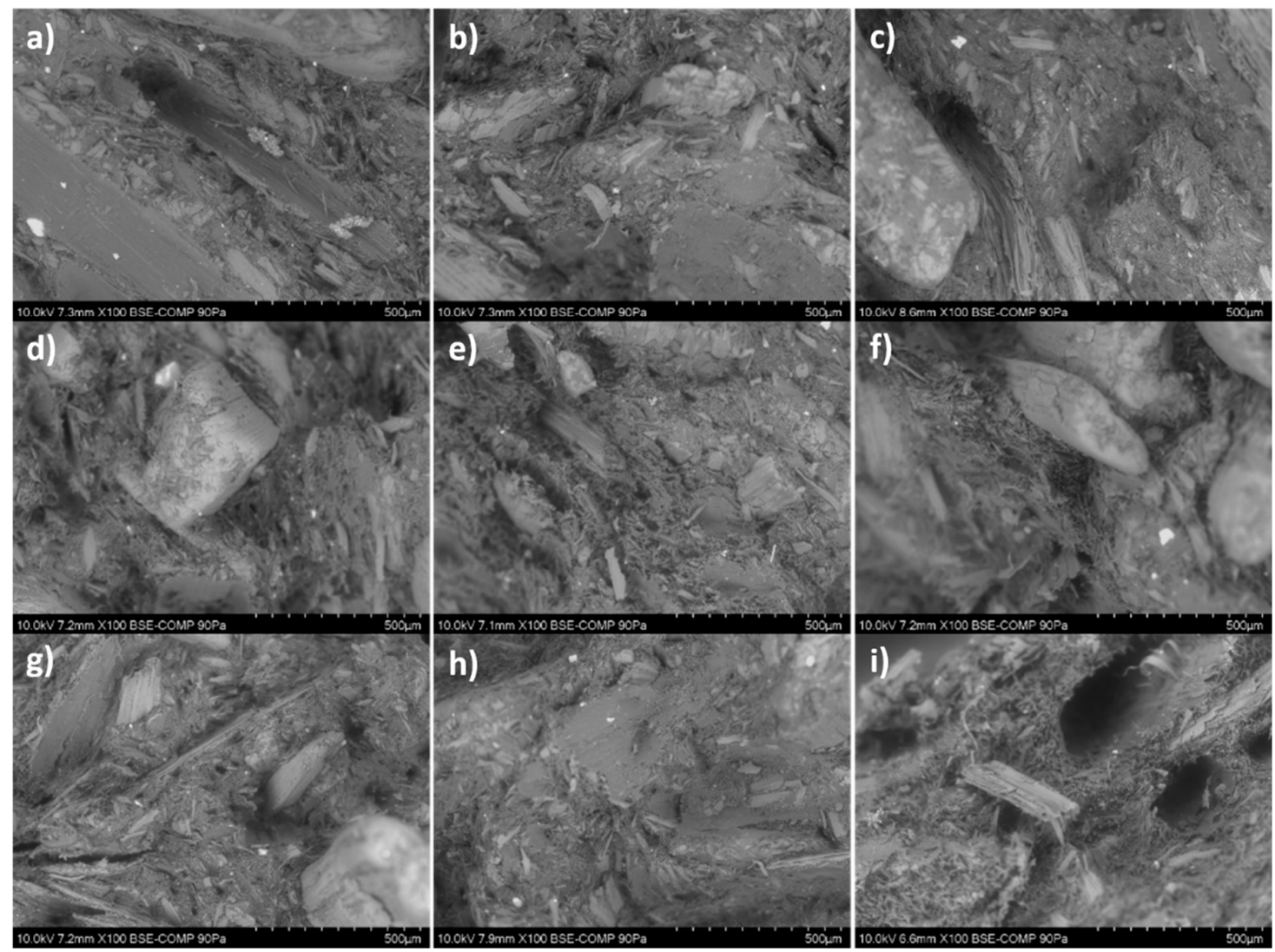

Figure 2. SEM images of the composites.

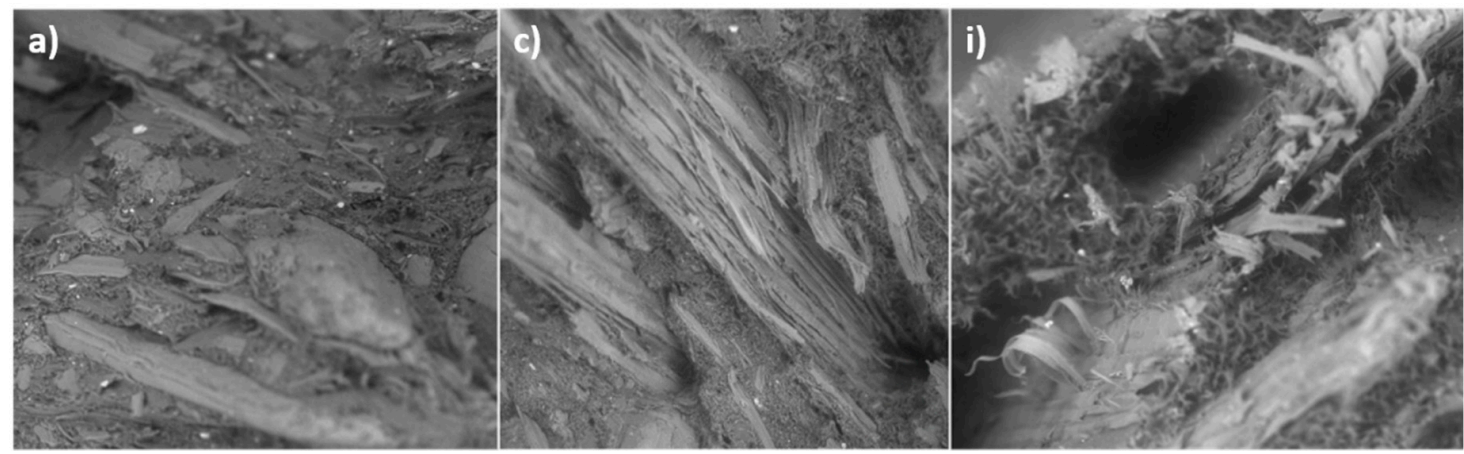

Figure 3. Enlarged details of (a): NC, (c): N525-7 and (i): MAM-7.

\subsection{Water Absorption and Thickness Swelling}

The highest water absorption after 28 days of immersion was found in material N416-3, 21.8\%, followed by NC with water absorption of $21.2 \%$-no statistically significant difference between them was found at $95 \%$ confidence level. The lowest water absorption was determined for material MAM-7, $6.8 \%$. Materials N525-3 and CM-7 also had a final water absorption below $10 \%$. The evolution of water absorption in immersion over time is visualized in Figure 4. 


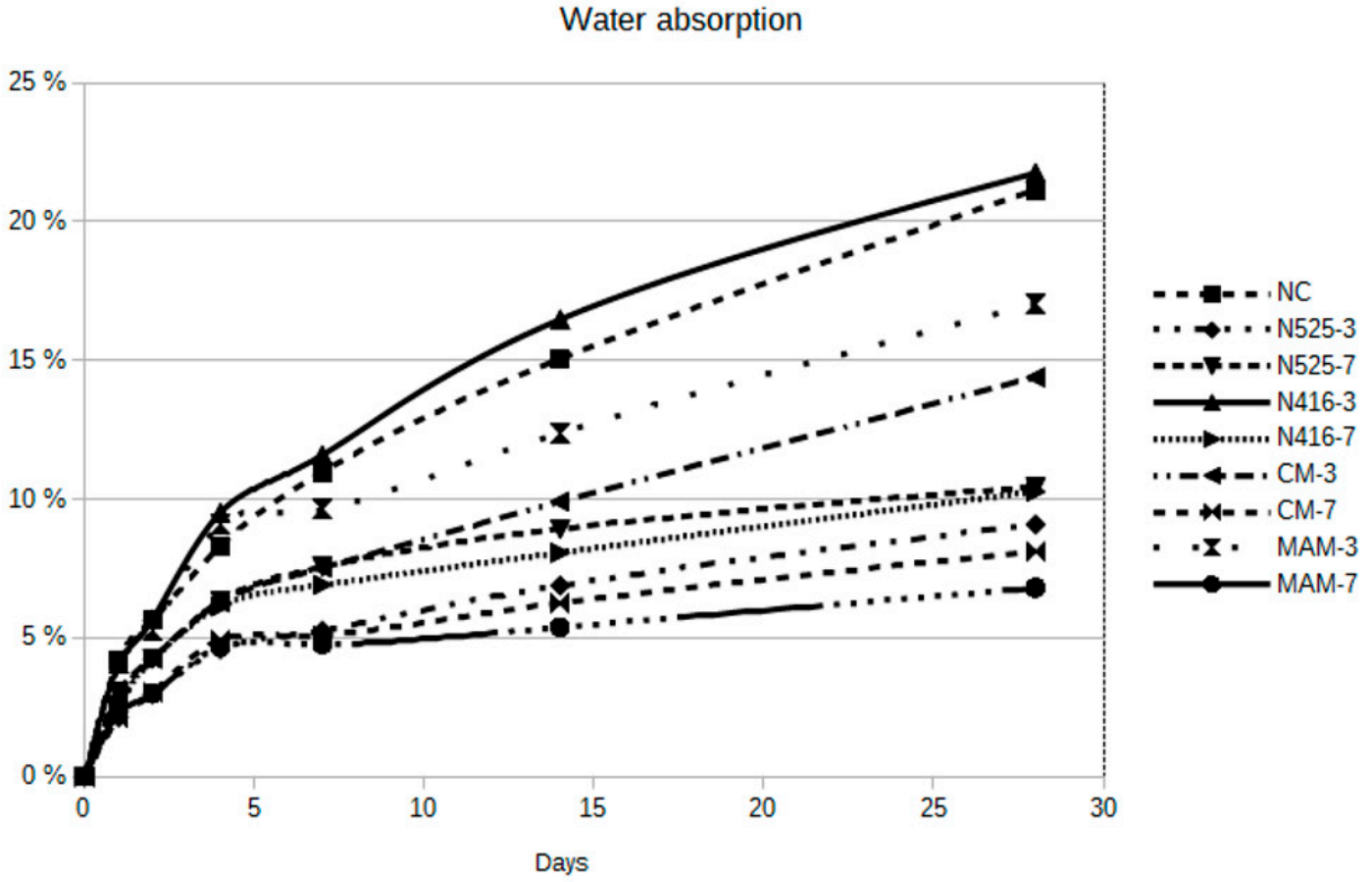

Figure 4. Water absorption, in weight-\%. Time in days.

The thickness swelling of the materials ranged from $2.5 \%$ for MAM-7 to $8.2 \%$ for NC after 28 days of immersion in water. The final thickness swelling for materials CM-7 and MAM-7 was only about $30 \%$ compared to NC. The general trend was that thickness swelling decreased notably as the amount of coupling agent increased, except with material N525. Thickness swelling over time is illustrated in Figure 5.

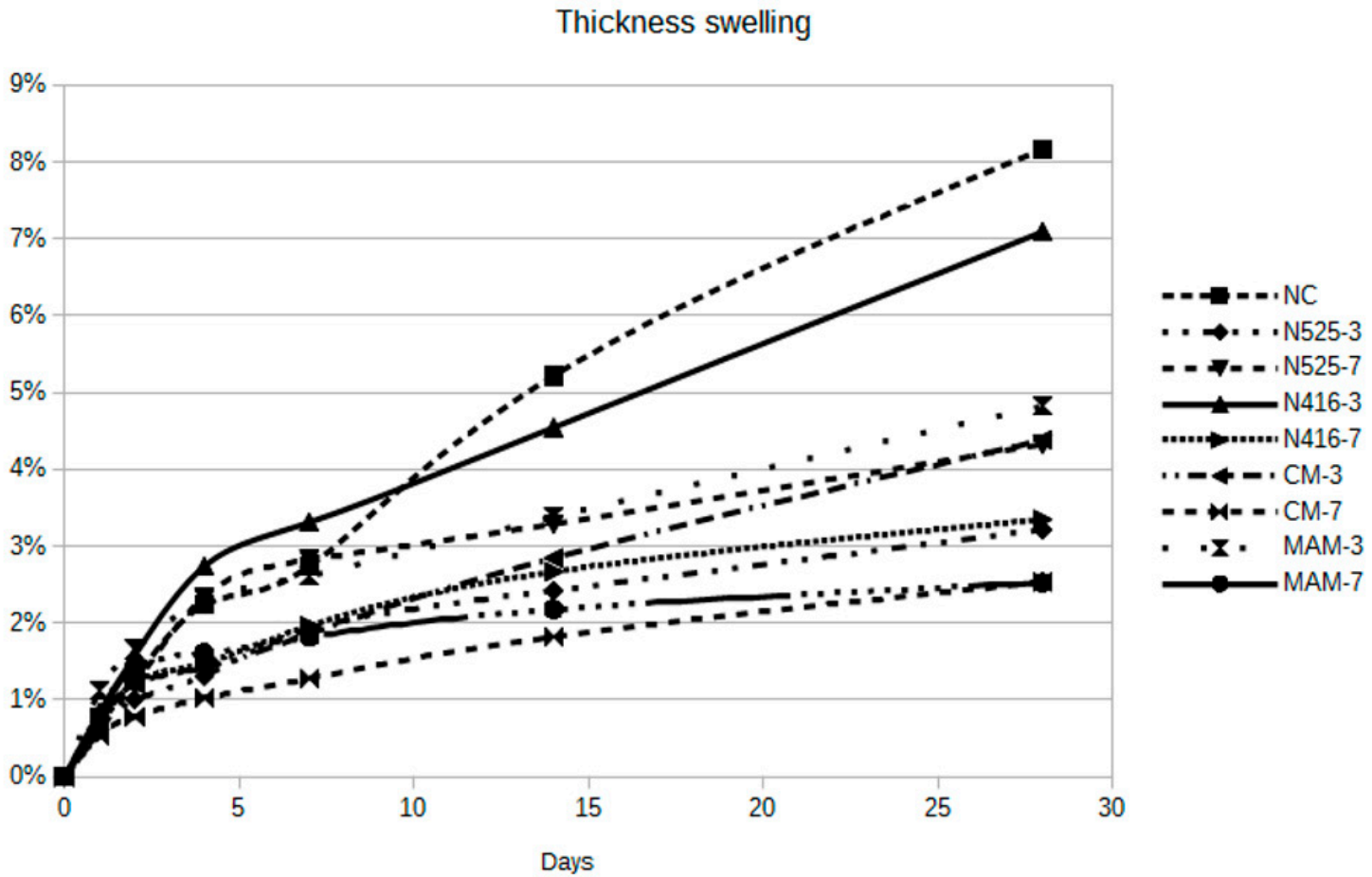

Figure 5. Thickness swelling of the materials in immersion. 


\subsection{Mechanical Properties}

Tensile strength and modulus, flexural strength and modulus, and Charpy impact strength were determined for the composites to reveal their mechanical properties and performance, in order to evaluate the effect of both the type and dosage of compatibilizers.

\subsubsection{Tensile Properties}

The tensile properties of materials are presented in Figure 6. The tensile strengths lie between 7.4 $\mathrm{MPa}$ and 11.8 $\mathrm{MPa}$. The highest tensile strength, 11.8 MPa, was recorded for material MAM containing $7 \mathrm{w}-\%$ of compatibilizers, being $59.8 \%$ higher than that of NC. The lowest values were found with NC and CM-3.

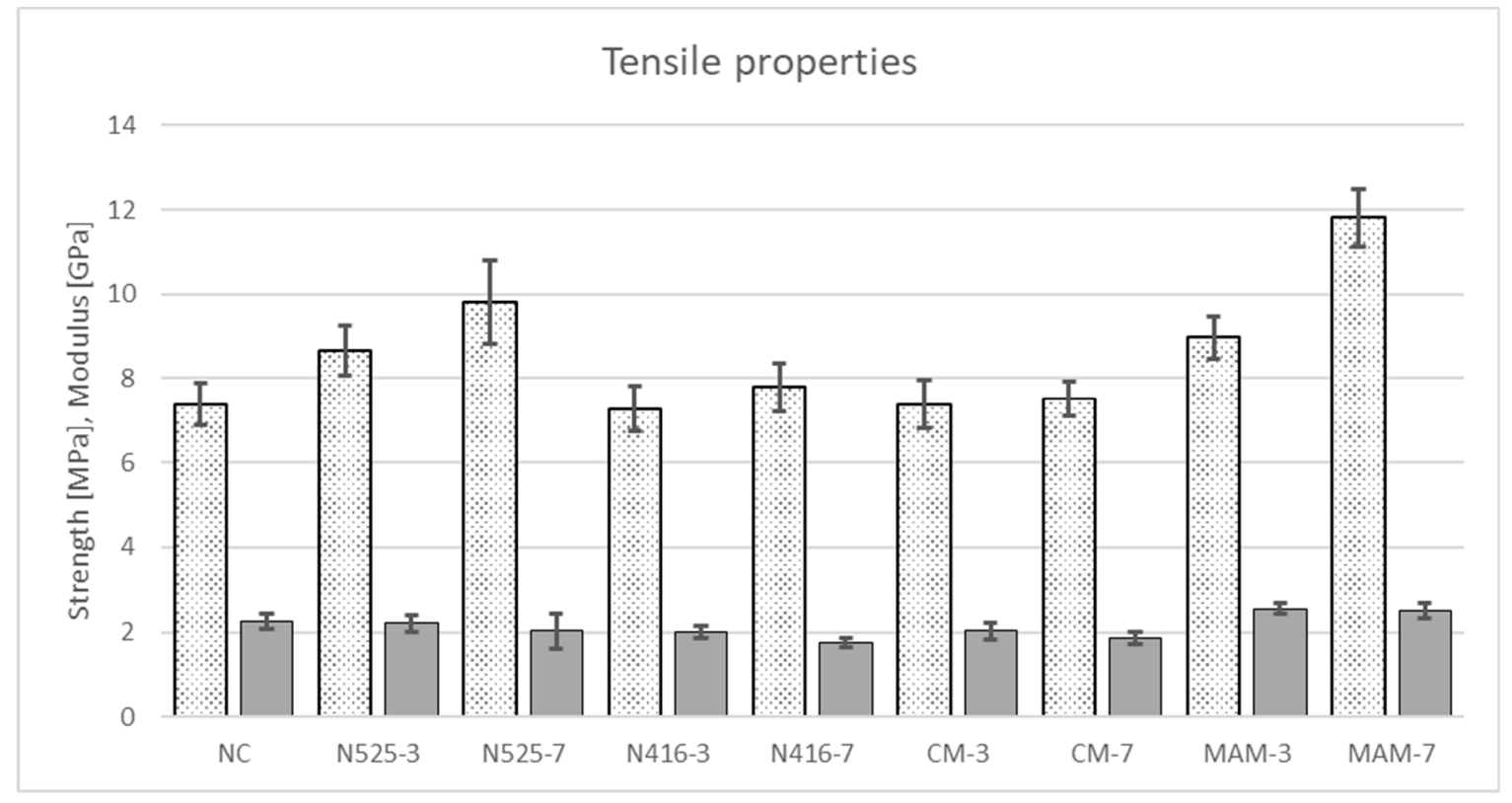

Figure 6. Tensile properties. Strength on the left side (light shaded bar) and modulus on the right (dark bar).

In general, the tensile strength showed an increasing trend with the increase of compatibilizer content, except for material CM. The tensile moduli lay between $1.7 \mathrm{GPa}$ (N416-7) and 2.6 GPa (MAM-3), while the material without compatibilizers had a tensile modulus of $2.3 \mathrm{GPa}$. Tensile performance relative to the reference material is presented in Table 1.

Table 1. Tensile properties relative to the reference. A difference not significant at $95 \%$ confidence level is marked with an asterisk $\left(^{*}\right)$.

\begin{tabular}{ccccccccc}
\hline Relative & N525-3 & N525-7 & N416-3 & N416-7 & CM-3 & CM-7 & MAM-3 & MAM-7 \\
\hline Strength & $17 \%$ & $33 \%$ & $-1 \% *$ & $5 \%$ & $0 \% *$ & $2 \% *$ & $22 \%$ & $60 \%$ \\
Modulus & $-3 \% *$ & $-11 \% *$ & $-12 \%$ & $-23 \%$ & $-11 \%$ & $-18 \%$ & $12 \%$ & $11 \%$ \\
\hline
\end{tabular}

Elongation at break is presented in Table 2. Both N525 and N416 showed over 1\% increase in the ductility of the composites at $7 \%$ addition level compared to the reference. No statistically significant difference at $95 \%$ confidence level was found between the reference and N416-3 or MAM-3. Elongation at break was increased with all compatibilizers at the $7 \%$ addition level. 
Table 2. Elongation at break with standard deviations. Insignificant changes compared to NC at $95 \%$ confidence level are marked with an asterisk $\left({ }^{*}\right)$.

\begin{tabular}{lccccccccc}
\hline & NC & N525-3 & N525-7 & N416-3 & N416-7 & CM-3 & CM-7 & MAM-3 & MAM-7 \\
\hline Mean & $0.58 \%$ & $0.77 \%$ & $1.02 \%$ & $0.63 \% *$ & $1.02 \%$ & $0.68 \%$ & $0.74 \%$ & $0.58 \% *$ & $0.81 \%$ \\
St.Dev. & $0.10 \%$ & $0.18 \%$ & $0.19 \%$ & $0.09 \%$ & $0.15 \%$ & $0.13 \%$ & $0.13 \%$ & $0.09 \%$ & $0.11 \%$ \\
\hline
\end{tabular}

\subsubsection{Flexural Properties}

The highest flexural strength was found with MAM-7, 17.65 MPa, and the lowest value was recorded for N416-3, 10.66 MPa. The reference material NC had the flexural strength of $11.27 \mathrm{MPa}$. In the case of flexural modulus, the highest value of $2.80 \mathrm{GPa}$ was found with the reference material NC and the lowest value with N525-7, 1.64 GPa. The flexural properties are presented in Figure 7, and a comparison of the flexural properties of the composites to the reference material, in percentages, is presented in Table 3.

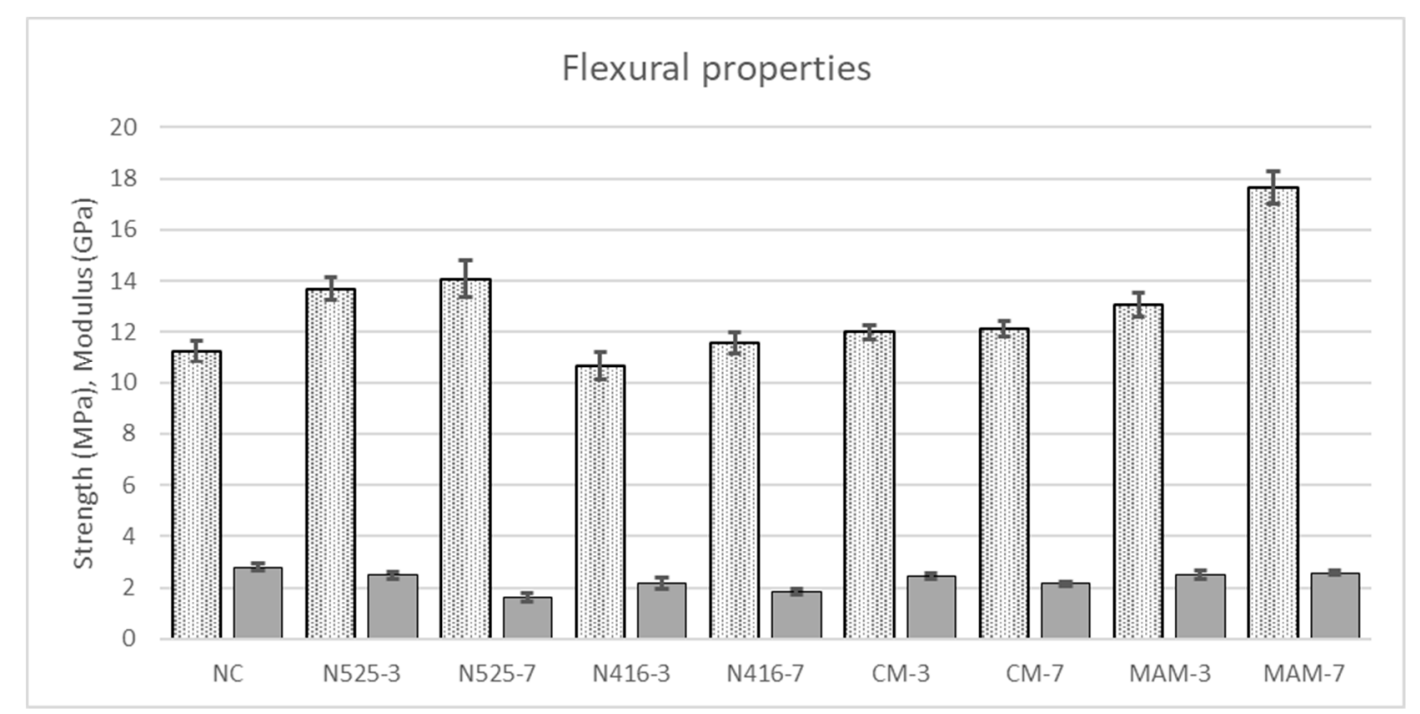

Figure 7. Flexural properties. Strength on the left side (light shaded bar) and modulus on the right (dark bar).

Table 3. Flexural properties compared to NC. All differences are significant at $95 \%$ confidence level.

\begin{tabular}{ccccccccc}
\hline Relative & N525-3 & N525-7 & N416-3 & N416-7 & CM-3 & CM-7 & MAM-3 & MAM-7 \\
\hline Strength & $21 \%$ & $25 \%$ & $-5 \%$ & $3 \%$ & $6 \%$ & $8 \%$ & $16 \%$ & $57 \%$ \\
Modulus & $-11 \%$ & $-42 \%$ & $-23 \%$ & $-34 \%$ & $-12 \%$ & $-23 \%$ & $-10 \%$ & $-8 \%$ \\
\hline
\end{tabular}

\subsubsection{Impact Strength}

The highest mean Charpy impact strength value was found with material N525-7, $6.4 \mathrm{~kJ} / \mathrm{m}^{2}, 61 \%$ higher than that $\left(4.0 \mathrm{~kJ} / \mathrm{m}^{2}\right)$ of the material made without compatibilizers (NC). N416-7 showed a $49 \%$ increase in impact strength, while materials CM-3 and MAM-3 did not indicate significant differences in impact strength compared to the reference at the $95 \%$ confidence level. The impact strengths are illustrated in Figure 8, and comparison to the reference in percentile is presented in Table 4. 


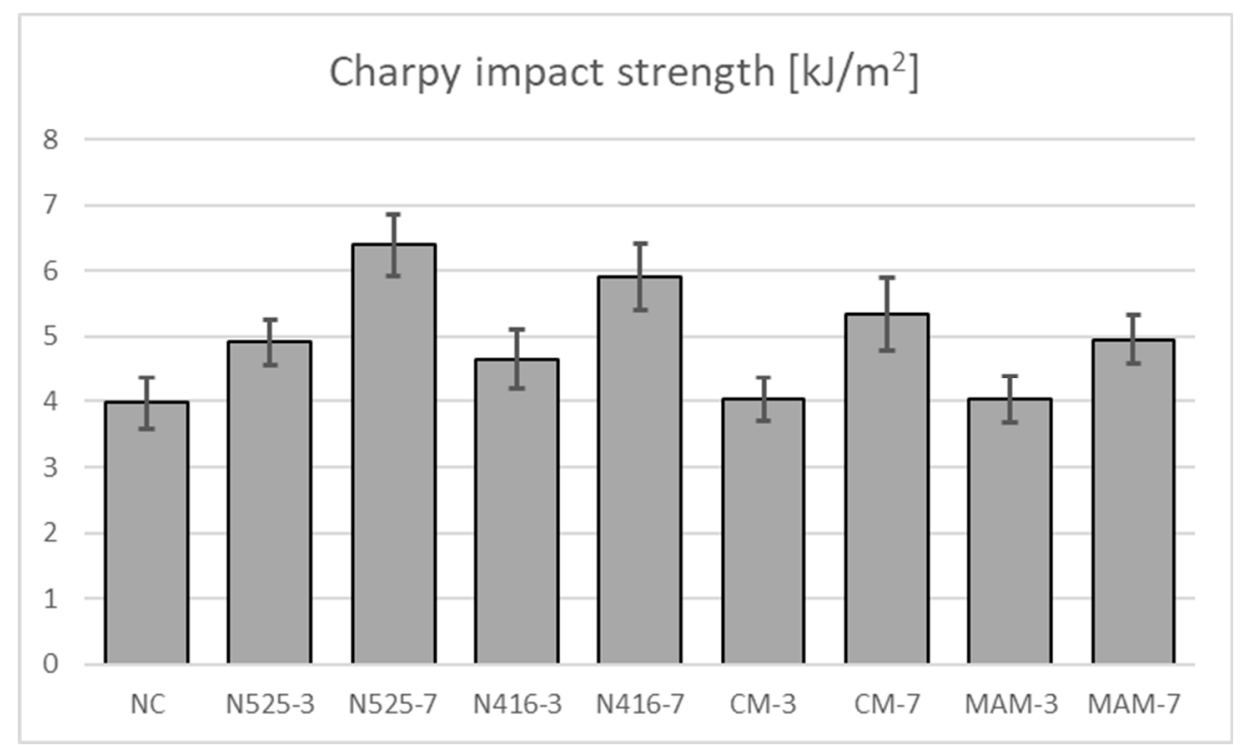

Figure 8. Charpy impact strengths with standard deviations.

Table 4. Impact strengths relative to the reference (NC). Differences not significant at the $95 \%$ confidence level are marked with an asterisk $(*)$.

\begin{tabular}{ccccccccc}
\hline Relative & N525-3 & N525-7 & N416-3 & N416-7 & CM-3 & CM-7 & MAM-3 & MAM-8 \\
\hline Charpy & $+24 \%$ & $+61 \%$ & $+17 \%$ & $+49 \%$ & $+2 \% *$ & $+34 \%$ & $+2 \%^{*}$ & $+25 \%$ \\
\hline
\end{tabular}

\subsection{Summary of Mechanical Properties}

In summary, the effect of different compatibilizers at different levels relative to the reference (NC) on moisture resistance and mechanical strengths are shown in Table 5. Higher values were considered better.

Table 5. Summary of different performances. Change in performance below $10 \%$ is marked with 0 , $10-24 \%$ with,$+ 25-50 \%$ with ++ , and an increase above $50 \%$ is marked with +++ .

\begin{tabular}{cccccc}
\hline \multirow{2}{*}{ Material } & \multicolumn{2}{c}{ Moisture } & Tensile Strength & Flexural Strength & Impact Strength \\
& Absorption & Swelling & Tmen & + \\
N525-3 & +++ & +++ & + & + & +++ \\
N525-7 & +++ & ++ & 0 & 0 & + \\
N416-3 & 0 & + & 0 & 0 & ++ \\
N416-7 & +++ & +++ & 0 & 0 & 0 \\
CM-3 & ++ & ++ & ++ & + & + \\
CM-7 & +++ & +++ & ++ & +++ & 0 \\
MAM-3 & + & ++ & ++ & ++ \\
MAM-7 & +++ & ++ & & & ++ \\
\hline
\end{tabular}

\subsection{Comparison to Commercial Composites}

To assess the significance of the change in properties caused by different compatibilizers and their effectiveness in promoting recyclability of waste plastics, properties of commercial WPCs (named after their manufacturer) and materials from the literature have been gathered into Table 6. along with the reference and MAM-7. Material C1 consists of $70 \%$ of wood fibres, $26 \%$ of virgin PP and $3 \%$ MAPP; in C2 the polymer used is recycled PP. The exact composition of the commercial materials is not known. 
Table 6. Physical properties of commercial WPCs and two produced. N/A denotes not available.

\begin{tabular}{cccc}
\hline Name & Flexural Strength [MPa] & Tensile Strength [MPa] & $\begin{array}{c}\text { Water Absorption in } \\
\text { 24h Immersion [\%] }\end{array}$ \\
\hline Newtechwood [31] & 26.2 & $\mathrm{~N} / \mathrm{A}$ & 0.49 \\
IDecking [32] & $\mathrm{N} / \mathrm{A}$ & $35.1^{\mathrm{a}}$ & $0.26^{\mathrm{b}}$ \\
Trex [33] & $25.9^{\mathrm{c}}$ & $\mathrm{N} / \mathrm{A}$ & $1.2^{\mathrm{d}}$ \\
Ecodek [34] & $22^{\mathrm{e}}$ & 10 & $0.6^{\mathrm{d}}$ \\
UPM ProFi [35] & 13 & $\mathrm{~N} / \mathrm{A}$ & $<2.5$ \\
C1 [26,27] & 25.4 & 18.2 & 3.7 \\
C2 [26,36] & 23.2 & 15.9 & 4.2 \\
Ref & 11.3 & 7.4 & 0.78 \\
MAM-7 & 17.7 & 11.8 & 0.74 \\
\hline
\end{tabular}

Test standards used (if not same with those used in this paper): (a) Unknown, (b) ASTM D570, (c) ASTM D4761, (d) ASTM D1037, e) ISO 178.

In general, there is a lot of variation between the properties of different commercial WPCs. Compared to the lowest reported values of the commercial materials, the properties of the best performing composite made (MAM-7) are within range.

\section{Materials and Methods}

\subsection{Materials and Preparation}

The plastic material used was obtained from a regional waste processing plant, Etelä-Karjalan Jätehuolto Oy, located in south-eastern Finland. The plastics originated from the South-Karelia region and comprised materials discarded from municipal, building and commercial sources. The used plastics were derived from the energy waste component, and the composition could be separated roughly into two categories: non-bottle rigid plastics and soft/film plastics. Only polyolefins were included in the study, as a substantial portion of plastic waste consists of a mixture of polyolefins, i.e., low and high density polyethylenes and polypropylene [37]. The materials were manually sorted on the basis of the markings on the items, so that the composition used in the experiments consisted of $1 / 3$ of PP and $2 / 3$ of PE (of weight,) which was considered to be the rough average of waste polyolefin plastics found at the site. The PP material consisted mainly of various discarded household goods, e.g., buckets, washing bins, flower pots, garden chairs etc. The PE material was composed mainly of plastic packaging films and bags.

The size of the plastic material was reduced by using an Untha LR630 shredder (Untha shredding technology $\mathrm{GmbH}$, Kuchl, Austria) equipped with a $20 \mathrm{~mm}$ sieve. The compatibilizers/coupling agents used in the study were commercially available. The materials were anhydride modified ethylene copolymer Fusabond N525, chemically modified ethylene elastomer Fusabond N416, anhydride modified polyethylene Fusabond E226, and ethylene copolymer resin Entira EP1754, which were obtained from DuPont de Nemours International Sàrl (Le Grand-Saconnex, Swizerland). According to the manufacturer, all these materials have a high maleic anhydride grafting level. Orevac CA100, grafted maleic anhydride functionalized polypropylene (Arkema Functional Polyolefins, Colombes Cedex, France). The physical properties of the compatibilizers are presented in Table 7. The mixture of Fusabond N416 and Entira EP1754 (CM) was inspired by advice from DuPont, and the mixture of maleated polyolefins (MAM) was fabricated to test the performance of a mixture of maleic crafted PE and PP, which had been previously used in WPCs in our laboratory. Naming of the compatibilizers used is shown in Table 8. The lubricant (processing additive) used was Struktol TPW 113 from Struktol Company of America (Stow, OH, USA). 
Table 7. Physical properties of the compatibilizers according to their manufacturers.

\begin{tabular}{ccccc}
\hline Name & Density $\left[\mathbf{g} / \mathbf{c m}^{\mathbf{3}}\right]$ & Melting Point $\left[{ }^{\circ} \mathrm{C}\right]$ & $\begin{array}{c}\text { Melt Flow Rate } \\
\text { (MFR) [g/10min] }\end{array}$ & $\begin{array}{c}\text { MFR Testing } \\
\text { Conditions }\end{array}$ \\
\hline Fusabond N525 & 0.88 & 54 & 3.7 & $190^{\circ} \mathrm{C} / 2.16 \mathrm{~kg}$ \\
Fusabond N416 & 0.869 & 43 & 23 & $190^{\circ} \mathrm{C} / 2.16 \mathrm{~kg}$ \\
Fusabond E226 & 0.93 & 120 & 1.75 & $280^{\circ} \mathrm{C} / 2.16 \mathrm{~kg}$ \\
Entira EP1754 & 0.965 & 47 & 52 & $190^{\circ} \mathrm{C} / 2.16 \mathrm{~kg}$ \\
Orevac CA100 & 0.905 & 167 & 10 & $190^{\circ} \mathrm{C} / 0.325 \mathrm{~kg}$ \\
\hline
\end{tabular}

Table 8. Naming of the compatibilizers used. The fractions present the weight ratio.

\begin{tabular}{cc}
\hline Naming Convention & Compatibilizer \\
\hline NC & - \\
N525 & Fusabond N525 \\
N416 & Fusabond N416 \\
CM & $2 / 3$ Entira EP1754 $+1 / 3$ Fusabond N416 \\
MAM & 2/3 Fusabond E226 + 1/3 Orevac CA100 \\
\hline
\end{tabular}

The wood material used in the composites was Spruce (Picea abies spp.) lumber that was processed with a crusher/shredder Untha LR630, and the particle size was further reduced by using a hammer mill Akron Nirvana FH 64-4-75 (Akronmaskiner, Järpås, Swerige) equipped with a $2 \mathrm{~mm}$ sieve, resulting in mean particle size $(\mathrm{L} / \mathrm{d})$ of $2.1 / 0.4(\mathrm{~mm})$ of the fibres. The particle size distribution is illustrated in Figure 9.

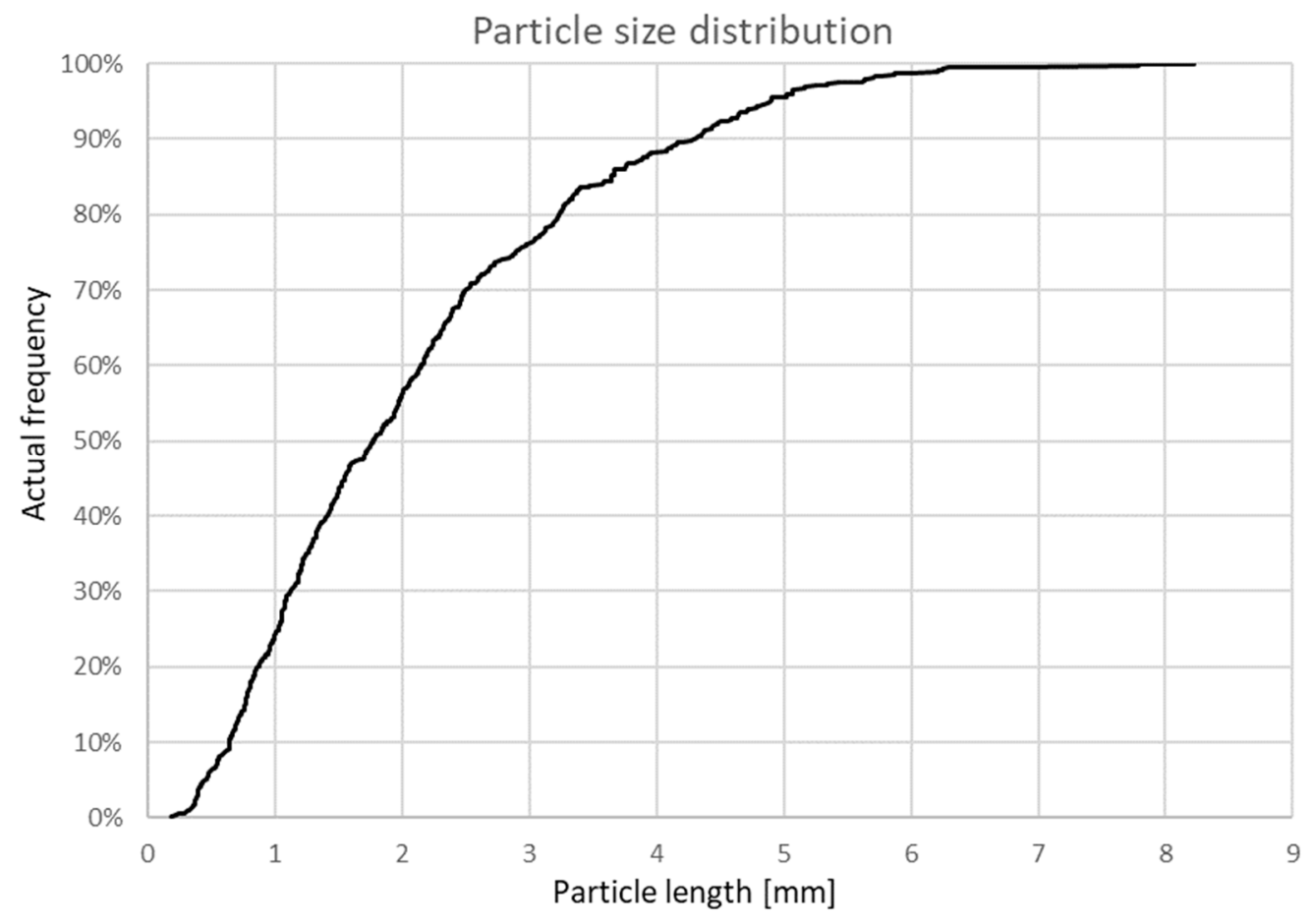

Figure 9. Particle size distribution of the wood material used in composites.

Prior to extrusion, the composite materials were agglomorated with an apparatus consisting of a Plas Mec TRL100/FV/W turbomixer and a Plas Mec RFV-200 cooler (Plas Mec S.R.L., Lonate Pozzolo, Varese, Italy). In agglomeration, the materials were mixed for approx. $23 \mathrm{~min}$, until the temperature of the mass reached $180^{\circ} \mathrm{C}$. No further drying of the materials was performed. The compositions and naming of the prepared materials are shown in Table 9. The naming is based on the naming of the compatibilizers used (Table 2) and the amount that were used (in weight- $\%$ ). 
Table 9. Test materials and their naming. The components are presented by percentage of weight.

\begin{tabular}{ccccc}
\hline Name & Wood fiber & Plastic & Compatibilizer & Lubricant \\
\hline NC & $57 \%$ & $40 \%$ & $0 \%$ & $3 \%$ \\
N525-3 & $54 \%$ & $40 \%$ & $3 \%$ & $3 \%$ \\
N525-7 & $50 \%$ & $40 \%$ & $7 \%$ & $3 \%$ \\
N416-3 & $54 \%$ & $40 \%$ & $3 \%$ & $3 \%$ \\
N416-7 & $50 \%$ & $40 \%$ & $7 \%$ & $3 \%$ \\
CM-3 & $54 \%$ & $40 \%$ & $3 \%$ & $3 \%$ \\
CM-7 & $50 \%$ & $40 \%$ & $7 \%$ & $3 \%$ \\
MAM-3 & $54 \%$ & $40 \%$ & $3 \%$ & $3 \%$ \\
MAM-7 & $50 \%$ & $40 \%$ & $7 \%$ & $3 \%$ \\
\hline
\end{tabular}

\subsection{Sample Preparation}

The agglomerate was extruded into a hollow profile by using a conical counter-rotating twin screw extruder, Weber CE 7.2 (Hans Weber Maschinenfabrik, Kronach, Germany), and then cut to test method-specific samples. The main extrusion parameters were: Screw speed $14 \mathrm{rpm}$, melt temperature $172{ }^{\circ} \mathrm{C}$, melt pressure $2.6 \mathrm{MPa}$, tool temperature $182{ }^{\circ} \mathrm{C}$. The test specimen for tensile and properties and impact strength were cut from the smooth surface of the hollow profile. Tensile specimens were then machined into shape 1A specified in the standard ISO 527-2. Impact strength specimens were unnotched having dimensions of $80 \times 10 \times 4 \mathrm{~mm}^{3}$. Bending test specimens were cut from the profile into specimens of a size of $450 \times 50 \times 20 \mathrm{~mm}^{3}$. Samples used in determination of moisture-related properties had dimensions of $50 \times 50 \times 20 \mathrm{~mm}^{3}$.

\subsection{Determination of Properties}

The mechanical performance of the materials was determined according to standards ISO 527-2/1A tensile strength and modulus; EN 310, bending strength and modulus; and ISO 179, Charpy impact strength. The Charpy impact strength was measured with a Zwick 5102 tester (Zwick GmbH \& Co. KG, Ulm, Germany), and the other mechanical properties were determined by using a Zwick-Roell Z020 universal testing apparatus (ZwickRoell GmbH \& Co.KG, Ulm, Germany). Water absorption (WA) and thickness swelling (TS) were determined according to EN 317 and calculated by using the following equations:

$$
\mathrm{WA}(\%)=\left(\mathrm{m}_{\mathrm{t}}-\mathrm{m}_{0}\right) / \mathrm{m}_{0} \times 100
$$

where $\mathrm{m}_{0}$ and $\mathrm{m}_{\mathrm{t}}$ are the mass of the sample before and after immersion.

$$
\mathrm{TS}(\%)=\left(\mathrm{T}_{\mathrm{t}}-\mathrm{T}_{0}\right) / \mathrm{T}_{0} \times 100
$$

where $T_{t}$ is the thickness of the sample after immersion, and $T_{0}$ is the thickness before immersion.

A minimum of 16 specimens per material were investigated. Statistical analyses ( $t$-tests for significance at $95 \%$ confidence level) were performed by using Statgraphics Plus 4 software (Statgraphics Technologies, Inc., The Plains, VA, USA).

The microstructures of the composites were studied by using a Hitachi SU3500 (Chiyoda, Tokyo, Japan) scanning electron microscope (SEM). The images were taken from the break-surfaces of the tested Charpy impact test specimens.

\section{Discussion}

The physical and mechanical properties of wood-commingled waste plastic composites manufactured by using different compatibilizers were studied. The results indicate that the properties can be improved by using compatibilizers, and different compatibilizers can impact different properties significantly, thus enabling recycling of mixed waste plastics in WPCs. 
Moisture resistance could be improved significantly by the addition of the selected compatibilizers. The reduction of water intake was decreased to one third of that of NC with MAM-7. With four of the materials (N525, N416, CM and MAM) at the 7\% compatibilizer level, the water absorption at 28 days was more than halved compared to the reference. Of those, only N525 provided the same performance also at the $3 \%$ addition level. In the case of thickness swelling, the results were congruent with water absorption, except that N525 swelled more at the 7\% addition level (4.33\%) than at the 3\% level (3.21\%). Similar behaviour with an increased MAPP content in WPCs has been reported previously by Ashori and Nourbakhsh [19]. Interestingly, in both water absorption and thickness swelling, material N525 performed better with 3\% compatibilizer level than with 7\% level. With all the other compatibilized materials, the swelling decreased by over $40 \%$ as the compatibilizer level increased, and a similar trend was found in the case of water absorption. The wood component in composites is mainly responsible for the water absorption and thickness swelling. The compatibilizers improve the properties of WPC due to the formation and increase of ester linkages between the hydroxyl groups of wood and the anhydride part of maleic grafted polymers [38]. The low performance of N416-3 suggests a lack of linking between the wood and compatibilizers, and thus a higher number of free hydroxyl groups in wood are capable of interacting with moisture. An increase in water absorption and thickness swelling as the compatibilizer content increased was found in N525. The moisture behavior of composites N416 and N525 can also be explained by their compatibilizer composition, as both are also used for polyamide blends, and polyamide is hygroscopic. An increase in water absorption as the amount of compatibilizer increases has been previously reported with recycled PET-PP blends [39]. Mechanical strength was in general affected and improved only by two compatibilizers, N525 and MAM. A higher level of addition gave better results; especially with MAM, the change was from a $22 \%$ improvement to a $60 \%$ improvement in tensile strength as the addition level rose from $3 \%$ to $7 \%$. A similar trend was evident with flexural strength with MAM; in the case of N525, the improvement was smaller, from $21 \%$ to $25 \%$, and not strongly related to the addition level. The increase in strength properties suggests improvement in adhesion between the wood component and the matrix in the composite, and signs of this can be seen in Figure 3. Both tensile and flexural modulus were decreased by more than $20 \%$ with N416, and impact strength was improved by $49 \%$ with N416-7. As fillers are generally responsible for the stiffness of composites, this result suggests improved compatibility between PP and PE in the matrix phase. The finding indicates that N416 can be used to modify the properties of composites towards flexibility and elasticity.

The level of addition had an apparent impact on the effect of the compatibilizers. In all cases, the trend was such that a $7 \%$ addition level had a stronger effect on the properties than a lower level, or a $7 \%$ addition level was needed to cause any notable change in the properties. Relatively high melt flow indexes along with low melt temperatures (Table 1) suggest that most of the compatibilizers studied are closer to elastomers in physical properties than to PP or HDPE. The compatibilizers with higher melt flow properties, i.e., N416 and CM (composed of Fusabond N416 and Entira EP1754), did not provide improvement in the tensility of flexural strength properties. The increase in viscosity of maleic compatibilizers with an increase in molecular weight has been reported by Kazushige et al. [40]. As the length of the individual polymer chain is proportional to molecular weight, this indicates that strength properties of the compatibilizer itself with high MFI and low melting temperature are expected to be relatively low on tensile strength and stiffness but higher on impact strength [41]. In general, impact strength and moisture resistance were strongly increased with an increase in compatibilizer content. In the case of N416 and CM, no notable effect on the strength properties was found, suggesting poor adhesion in the composite. Hence, it can be speculated that $7 \%$ addition level increased the performance also by the addition of polymer content in addition to interactions in the matrix phase. It is known, that if cellulosic fibers were totally encapsulated by a hydrophobic polymer, they were protected from moisture. At wood loadings of $40 \%$ or higher, the encapsulation of wood fibers in the composite is not complete [15,42,43]. With $7 \%$ compatibilizer addition, the fiber content in composites was reduced to $50 \%$, which is relatively close to the $40 \%$ threshold. 
The best overall single additive solution tested was N525 at the 7\% addition level. Also, depending on the raw materials used in the production of the composites, it appears that the mixing of different compatibilizers may be feasible. Good overall performance compared to the reference was found in the composite made with a mixture of two compatibilizers, MAM, at a 7\% dosage. This compatibilizer also increased the tensile modulus, providing more stiffness.

Comparison of the best performing materials produced with commercial WPCs (Table 9) show that the best compatibilization studied improves the performance of the composite close to that of commercial materials. Also, there was no difference of a magnitude between the performance of materials $\mathrm{C} 1$ and $\mathrm{C} 2$, suggesting that the use of one kind of recycled polymer to replace virgin polymers is feasible. However these materials had a significantly higher moisture absorption than the other materials, which can be attributed to their higher wood content, which is irrelevant to the polymer source. The performance of the N525-7 and MAM-7 made of mixed waste polymers is in the range or above the lowest reported values of the commercial materials, but a substantial improvement is still needed to meet the performance of the best performing commercial materials. It has to be noted that different test standards were used to evaluate the properties of commercial WPCs, making a direct comparison impossible.

A relatively high amount of compatibilizers was studied, and the best performance of the composites was achieved at the highest $7 \%$ level of compatibilization. This is in contradiction with some previously published papers showing that the highest performance of WPCs are achieved at compatibilizer levels of $3-4 \%$, and the performance starts to decrease at higher levels $[27,44]$. This suggests that compatibilization of plastic mixtures with wood fibres is more challenging, and to achieve an increase in mechanical performance, a higher compatibilizer content that is typically used is required. The optimization of the amount and type of compatibilization in wood-mixed waste polymer composites still needs further research.

\section{Conclusions}

The properties of nine different wood-mixed waste plastic composites having different compatibilizers at different levels were studied. The key findings were:

- Inexpensive mixed waste plastics can be recycled as feedstock for WPCs using selected compatibilizers.

- In moisture resistance, a $7 \%$ addition level was in general needed to improve the performance by over $50 \%$.

- $\quad$ N416 at the 7\% level modified both tensile and flexural moduli by over $23 \%$ toward more plastic behaviour. Impact strength was also increased by $49 \%$ compared to the reference.

- Two tested compatibilizers improved all the properties more than by $25 \%$ at the $7 \%$ addition level: N525 and MAM, a mixture of Fusabond E226 and Orevac CA100.

- The findings indicate that different properties are affected by the addition of different compatibilizers.

- The results also suggest that blends of different compatibilizers may be used to tailor the properties of wood-mixed waste plastic composites.

- The performance of wood-mixed waste plastic composites can be improved to be close to those of commercial WPCs, providing a feasible mean for recycling mixed waste plastics.

Author Contributions: Conceptualization and methodology, T.K. and O.M.; formal analysis, investigation and data curation, O.M.; writing-original draft preparation, O.M.; writing—review and editing, O.M. and T.K.; visualization, O.M.; supervision and administration, T.K.

Acknowledgments: This research was funded by the European Regional Development Fund, grand A71163: Material effective circular economy in Northern Savonia.

Conflicts of Interest: The authors declare no conflict of interest. 


\section{References}

1. PlasticsEurope. Available online: https://www.plasticseurope.org/en/resources/publications/274-plasticsfacts-2017 (accessed on 5 October 2018).

2. Hopewell, J.; Dvorak, R.; Kosior, E. Plastics recycling: Challenges and opportunities. Philos. Trans. R. Soc. London, Ser. B 2009, 364, 2115-2126. [CrossRef] [PubMed]

3. EPA Overview of Greenhouse Gases. Available online: https://www.epa.gov/ghgemissions/overviewgreenhouse-gases (accessed on 29 November 2018).

4. Lindsey, R. Climate Change: Atmospheric Carbon Dioxide. Available online: https://www.climate. gov/news-features/understanding-climate/climate-change-atmospheric-carbon-dioxide (accessed on 28 November 2018).

5. European Comission. Available online: http://ec.europa.eu/environment/waste/framework/ (accessed on 8 August 2018).

6. Adewole, A.A.; Wolkowicz, M.D. Recycling of Polypropylene and Its Blends: Economic and Technology Aspects. In Handbook of Polypropylene and Polypropylene Composites; Karian, H., Ed.; Marcel Dekker, Inc.: New York, UY, USA, 2003; pp. 127-168.

7. Al-Salem, S.M.; Lettieri, P.; Baeyens, J. Recycling and recovery routes of plastic solid waste (PSW): A review. Waste Manage. 2009, 29, 2625-2643. [CrossRef] [PubMed]

8. Patel, M.; von Thienen, N.; Jochem, E.; Worrell, E. Recycling of plastics in Germany. Resour Conserv Recycl 2000, 29, 65-90. [CrossRef]

9. Turku, I.; Keskisaari, A.; Kärki, T.; Puurtinen, A.; Marttila, P. Characterization of wood plastic composites manufactured from recycled plastic blends. Compos. Struct. 2017, 161, 469-476. [CrossRef]

10. Utracki, L.A. Reprocessing of Commingled Polymers and Recycling of Polymer Blends. In Frontiers in the Science and Technology of Polymer Recycling; Akovali, G., Bernardo, C.A., Leidner, J., Utracki, L.A., Xanthos, M., Eds.; Springer Netherlands: Dordrecht, The Netherlands, 1998; pp. 333-354.

11. La Mantia, F.P.; Scaffaro, R. Recycling Polymer Blends. In Polymer Blends Handbook; Utracki, L.A., Wilkie, C.A., Eds.; Polymer Blends Handbook; Springer: Dordrecht, The Netherlands, 2014; pp. 1885-1913.

12. Ragaert, K.; Delva, L.; Van Geem, K. Mechanical and chemical recycling of solid plastic waste. Waste Manage. 2017, 69, 24-58. [CrossRef]

13. CEN EN 15534-1:2014. Composites made from cellulose-based materials and thermoplastics (usually called wood-polymer composites (WPC) or natural fibre composites (NFC))-Part 1: Test methods for characterisation of compounds and products. 2014.

14. Kim, J.K.; Pal, K. Effect of Compatibilizers in WPC Composites. In Recent Advances in the Processing of Wood-Plastic Composites; Springer Berlin Heidelberg: Berlin, Heidelberg, 2011; pp. 103-127.

15. Klyosov, A.A. Wood-plastic composites; Wiley-Interscience: Hoboken, NJ, USA, 2007; p. 726.

16. Sardot, T.; McDonald, A.G.; Smith, G. Characterization of a Cardboard Recycling Facility's Mixed Plastic Waste for Beneficial Use. Waste Biomass Valori. 2013, 4, 161-171. [CrossRef]

17. Rajendran, S.; Scelsi, L.; Hodzic, A.; Soutis, C.; Al-Maadeed, M.A. Environmental impact assessment of composites containing recycled plastics. Resour. Conserv. Recycling 2012, 60, 131-139. [CrossRef]

18. Adhikary, K.B.; Pang, S.; Staiger, M.P. Dimensional stability and mechanical behaviour of wood-plastic composites based on recycled and virgin high-density polyethylene (HDPE). Compos. Part B 2008, 39, 807-815. [CrossRef]

19. Ashori, A.; Nourbakhsh, A. Characteristics of wood-fiber plastic composites made of recycled materials. Waste Manage. 2009, 29, 1291-1295. [CrossRef]

20. Binhussain, M.A.; El-Tonsy, M.M. Palm leave and plastic waste wood composite for out-door structures. Constr. Build. Mater. 2013, 47, 1431-1435. [CrossRef]

21. Cui, Y.; Lee, S.; Noruziaan, B.; Cheung, M.; Tao, J. Fabrication and interfacial modification of wood/recycled plastic composite materials. Compos. Part A 2008, 39, 655-661. [CrossRef]

22. Jayaraman, K.; Bhattacharyya, D. Mechanical performance of woodfibre-waste plastic composite materials. Resour. Conserv. Recycling 2004, 41, 307-319. [CrossRef]

23. Kazemi, Y.; Cloutier, A.; Rodrigue, D. Mechanical and morphological properties of wood plastic composites based on municipal plastic waste. Polym. Compos. 2013, 34, 487-493. [CrossRef] 
24. Najafi, S.K.; Hamidinia, E.; Tajvidi, M. Mechanical properties of composites from sawdust and recycled plastics. J. Appl. Polym. Sci. 2006, 100, 3641-3645. [CrossRef]

25. Yadav, A.K.; Srivastava, R. Recycling and reuse of plastic and wood waste for fabrication of wood plastic composite for engineering applications. Discovery 2015, 41, 20-25.

26. Butylina, S.; Martikka, O.; Kärki, T. Physical and Mechanical Properties of Wood-Polypropylene Composites Made with Virgin and/or Recycled Polypropylene. Polym. Plast. Technol. Eng. 2011, 50, 1040-1046. [CrossRef]

27. Keener, T.; Stuart, R.; Brown, T. Maleated coupling agents for natural fibre composites. Compos. Part A 2004, 35, 357-362. [CrossRef]

28. Lu, J.Z.; Wu, Q.; McNabb, H.S. Chemical coupling in wood fiber and polymer composites: A review of coupling agents and treatments. Wood Fiber Sci. 2007, 32, 88-104.

29. Gao, H.; Xie, Y.; Ou, R.; Wang, Q. Grafting effects of polypropylene/polyethylene blends with maleic anhydride on the properties of the resulting wood-plastic composites. Compos. Part A 2012, 43, 150-157. [CrossRef]

30. Liu, N.C.; Huang, H. Types of Reactive Polymers Used in Blending. In Reactive Polymer Blending; Baker, W.E., Scott, C.E., Hu, G., Eds.; Carl Hanser Verlag GmbH \& Co. KG: Munich, Germany, 2001; pp. 13-42.

31. Newtechwood Decking Naturale (Hollow) Technical Sheet. Available online: http://www.newtechwood. com/pdf/Decking_Naturale_Hollow__Technical_Sheet.pdf (accessed on 11 December 2018).

32. iDeck material characteristics. Available online: https://www.idecksystems.com/en/materials/duro (accessed on 11 December 2018).

33. Trex Technical Information. Available online: https://uk.trex.com/trex-owners/downloads/\#technicalinfo (accessed on 11 December 2018).

34. ecodek Physical Properties. Available online: https://s3-eu-west-1.amazonaws.com/ecodek/PDF/Data+ Sheet+2+-+Technical+Data+v3.4.pdf (accessed on 11 December 2018).

35. UPM Technical Specification. Available online: https://www.upmprofi.com/siteassets/documents/ technical-documents/upm-profi-deck-technical-en.pdf (accessed on 11 December 2018).

36. Butylina, S.; Martikka, O.; Kärki, T. Comparison of water absorption and mechanical properties of wood-plastic composites made from polypropylene and polylactic acid. Wood Mater. Sci. Eng. 2010, 5, 220-228. [CrossRef]

37. Chodak, I. Improving the Properties of Polyolefin Waste by Reactive Processing. Polym. Plast. Technol. Eng. 2004, 43, 1769-1777. [CrossRef]

38. Mishra, S.; Jagmohan, V. Effect of compatibilizers on water absorption kinetics of polypropylene/wood flour foamed composites. J. Appl. Polym. Sci. 2006, 101, 2530-2537. [CrossRef]

39. Aminuddin, S.F.; Wei, L.Y.; Hamada, H.; Adnan, N. 2012 IEEE Symposium on Humanities, Science and Engineering Research. In Recycled poly(ethylene terephthalate)/recycled polypropylene blend: Effect of hygrothermal treatment; IEEE: New York, UY, USA, 2012; pp. 239-244.

40. Murayama, K.; Suzuki, S.; Kojima, Y.; Kobori, H.; Ito, H.; Ogoe, S.; Okamoto, M. The Effects of Different Types of Maleic Anhydride-Modified Polypropylene on the Physical and Mechanical Properties of Polypropylene-based Wood/Plastic Composites. J. Wood Chem. Technol. 2018, 38, 224-232. [CrossRef]

41. Gent, A.N.; Thomas, A.G. Effect of molecular weight on the tensile strength of glassy plastics. J. Polym. Sci. A-2 Polym. Phys. 1972, 10, 571-573. [CrossRef]

42. Stark, N. Influence of Moisture Absorption on Mechanical Properties of Wood Flour-Polypropylene Composites. J. Thermoplast. Compos. Mater. 2001, 14, 421-432. [CrossRef]

43. Teacă, C.; Bodîrlău, R.; Spiridon, I. Maleic anhydride treatment of softwood-effect on wood structure and properties. Cellul. Chem. Technol. 2014, 48, 863-868.

44. Sain, M.; Suhara, P.; Law, S.; Bouilloux, A. Interface Modification and Mechanical Properties of Natural Fiber-Polyolefin Composite Products. J. Reinf. Plast. Compos. 2005, 24, 121-130. [CrossRef]

(C) 2019 by the authors. Licensee MDPI, Basel, Switzerland. This article is an open access article distributed under the terms and conditions of the Creative Commons Attribution (CC BY) license (http:/ / creativecommons.org/licenses/by/4.0/). 